\title{
Mathematical Modeling For Multi-Layer Optical Fibers
}

$\begin{array}{ccc}\begin{array}{c}\text { Dr. Maan M.Shaker } \\ \text { Assistant Professor }\end{array} & \begin{array}{c}\text { Dr. Abdulghafoor I. Abdullah } \\ \text { Assistant Professor }\end{array} & \begin{array}{c}\text { Dr. Manaf G. Said } \\ \text { Lecturer } \\ \text { mnf_1959@yahoo.com }\end{array} \\ \text { maanms_56@yahoo.com } & \text { ghaaa4@yahoo.com } & \end{array}$

\section{Abstract}

A mathematical model to solve a scalar wave equation based on weakly guiding approximation for multi-layer (or multi-step) optical fibers is numerically carried out. The suggested numerical method is suitable to any multi- layer index profile (including W-fiber and conventional fiber) and sufficiently accurate if fiber materials for successive layers have small index differences. The general characteristics of multi-layer fiber such as cutoff wavelength and dispersion are obtained employing this model.

Keywords: optical fiber, multi-layer and dispersion

$$
\begin{aligned}
& \text { التمثيل الرياضي للألياف الضوئية متعددة الطبقات } \\
& \text { د.عبد الغفور إبراهيم عبد الله د. مناف غانم سعيد } \\
& \text { أستاذ مساعد الماه }
\end{aligned}
$$

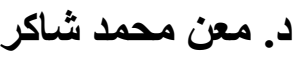

$$
\begin{aligned}
& \text { أستاذ مساعد } \\
& \text { كليــة التربيـة/ قســـم الفيزيــاء كليـة } \\
& \text { الكلية التقنية }
\end{aligned}
$$

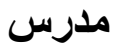

$$
\begin{aligned}
& \text { التربية/ قسم الفيزياء }
\end{aligned}
$$

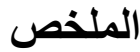




\section{$\underline{\text { Introduction }}$}

Communication using optical fiber as transmission media has become vast in evolving industries. The success of a given optical system depends directly on the choice of fiber parameters; including geometrical dimensions, material composition and the refractive index profile. All influence the various linear and nonlinear fiber behaviors, and must be carefully chosen in order to achieve optimal performance. The most important fiber characteristics, which have to be found using some numerical calculation, are fiber propagation constant, dispersion, dispersion slope, cutoff wavelength and field distribution. Most significant fiber feature is the ability to predict how any given fiber parameters can be optimized versus a design goal, such that low (nearzero) dispersion is obtained for a given wavelength range or at least at some predetermined wavelength. The benefit of this work is dramatic reduction of investment risk and time-to-market, rapid, low cost prototyping, performance evaluation of various types of fibers before actual manufacturing, assessment of parameters, sensitivities, tolerances and how the changes of design parameters affect fiber characteristic. The design of a single-mode optical fiber should have several conditions: low transmission loss, single-mode and zero or small total dispersion over wide-bandwidth. Employing refractive index profile with multi-layer index is carried out in order to manipulate with such profile to achieve inter-balance between waveguide and chromatic dispersion. Hence, a low or near zero dispersion fiber are achieved. The wavelength dependence of the refractive index defined by Sellmeier formula is given by the following relation [1]:

$$
\mathrm{n}(\lambda)=\left[1+\sum_{\mathrm{i}=1}^{3} \frac{\mathrm{A}_{\mathrm{i}} \lambda^{2}}{\lambda^{2}-\lambda_{\mathrm{i}}^{2}}\right]^{1 / 2}
$$

where $\lambda$ is the operating wavelength, $\lambda_{\mathrm{i}}, A_{\mathrm{i}}(\mathrm{i}=1,2,3)$ are the Sellmeier coefficients whose measured values are available for number of silicabased materials used for fiber fabrication [1].

\section{Some Useful Parameters}

The following fiber parameters are the most significant that are frequently used when dealing with fibers in general and they are:

\section{1-Normalized frequency $(\mathrm{V})$}


It is very useful parameter, which summarized all the important characteristics of the fiber in single number. It can be used to determine if the fiber will be in single mode or not at particular wavelength, also to calculate the number of possible modes. Moreover, it can be used to calculate the cutoff wavelength [2].

$$
\mathrm{V}=\frac{2 \pi \mathrm{d}}{\lambda} \sqrt{\mathrm{n}_{\text {max }}^{2}-\mathrm{n}_{\text {clad }}^{2}}
$$

where d: ${ }_{1}^{\lambda}$ the core radius, $n_{\max }$ is the maximum refractive index of the core while $\mathrm{n}_{\text {clad }}$ is the refractive index of the outer cladding layer. It is worth noting that if $\mathrm{V} \leq 2.405$, the fiber will be single mode at specific wavelength.

\section{2-Effective refractive index $\left(\mathrm{n}_{\text {eff }}\right)$}

It is a single number situated between the refractive index of the core (max. refractive index) and cladding refractive index, which summarized the effect of both [1].

$$
\mathrm{n}_{\text {eff }}=\frac{\beta}{\mathrm{k}}
$$

where $\beta$ is the propagation constant and $\mathrm{k}$ is the wave number, $\mathrm{k}=2 \pi / \lambda$.

\section{3-Propagation constant ( $\beta$ )}

The wave is guided in a specific mode fiber if $(\beta)$ the "propagation constant" satisfies:

$$
\mathrm{kn}_{\max }>\beta>\mathrm{kn}_{\text {clad }} \text {. }
$$

and the normalized propagation constant $b$ is [3]:

$$
b=\frac{\left(n^{2}{ }_{\text {effi }}-n^{2} \text { dad }\right)^{1 / 2}}{\left(n^{2}{ }_{\text {max }}-n^{2}{ }_{\text {dad }}\right)^{1 / 2}}=\frac{\left((\beta / k)^{2}-n^{2}{ }_{\text {dad }}\right)^{1 / 2}}{\left(n^{2}{ }_{\text {max }}-n^{2}{ }_{\text {dad }}\right)^{1 / 2}}
$$

The normalized propagation constant is in the range $0 \leq \mathrm{b} \leq 1$.

\section{4-Cutoff wavelength $\left(\lambda_{c}\right)$}

In general, the cutoff wavelength is the wavelength at which the fiber will have the relation $\beta=\mathrm{kn}_{\text {clad. }}$. In case that the operating wavelength is longer than the cutoff, the light waves will travel in the previous mode. When wavelengths are shorter than the cutoff the light wave will travel in bimodal dispersion. Note that wavelengths that makes (V) less than 2.405 (the cutoff wavelength) the light waves will travel in a single mode. The 
cutoff wavelength of any LP higher order mode can be calculated after defining the fiber profile and determining the propagation constant [4].

\section{5-Dispersion (D)}

Dispersion is the spreading of light pulses such that a pulse may join with the pulse behind, making recovery of reliable bit stream impossible. As they travel down optical fiber, the result in distortion of signal could take place. Since modal dispersion cannot occur in singlemode fiber because it has only one mode, the major sources of dispersion are material (or chromatic) dispersion and waveguide dispersion [5]. Total dispersion can be calculated by the numerical derivation of the effective refractive index as a function of the wavelength. The dispersion is calculated from the following relationship [6]:

$$
D=-\frac{\lambda}{c} \frac{d^{2} n_{\text {eff }}}{d \lambda^{2}}
$$

\section{6-Dispersion slope (second order dispersion)}

Dispersion slope is the rate of change of dispersion with wavelength [4]. In Wavelength Division Multiplexing (WDM) it is desirable to have all the channels experience a similar dispersion coefficient in order to reduce the costs associated with dispersion management. For this reason fibers with reduced slope have developed

$$
\frac{d D}{d \lambda}=-\frac{1}{c}\left[\frac{d^{2} n_{e f f}}{d \lambda^{2}}+\lambda \frac{d^{3} n_{e f f}}{d \lambda^{3}}\right]
$$

for multi-channel application. Such a fiber is called dispersion-flattened fiber. The dispersion slope is calculated from the following relation:

\section{The Suggested Model for Multi-Layer Fiber and the Numerical Solution:}

Consider an N-layer optical fiber of cylindrical shape consisting of a central core region and several claddings, $a_{i}$ is the radius of the $i^{\text {th }}$ layer, as shown in Fig. (1). All layers are assumed to be concentric, lossless and their refractive indices are homogenous. The $\mathrm{i}^{\text {th }}$ layer is referring to the number of cladding layer, $(i=1,2,3 \ldots \mathrm{N}$; $\mathrm{N}$ : number of layers); $\mathrm{r}$ : is the distance from core center. 
$\nabla^{2} E+k^{2} n^{2} E=0$

It is suitable to start from the homogenous vector wave equation [2] to determine the required propagation characteristics in cylindrical fibers:

where $\mathbf{E}$ is the electric field and $\mathbf{H}$ is the magnetic field.

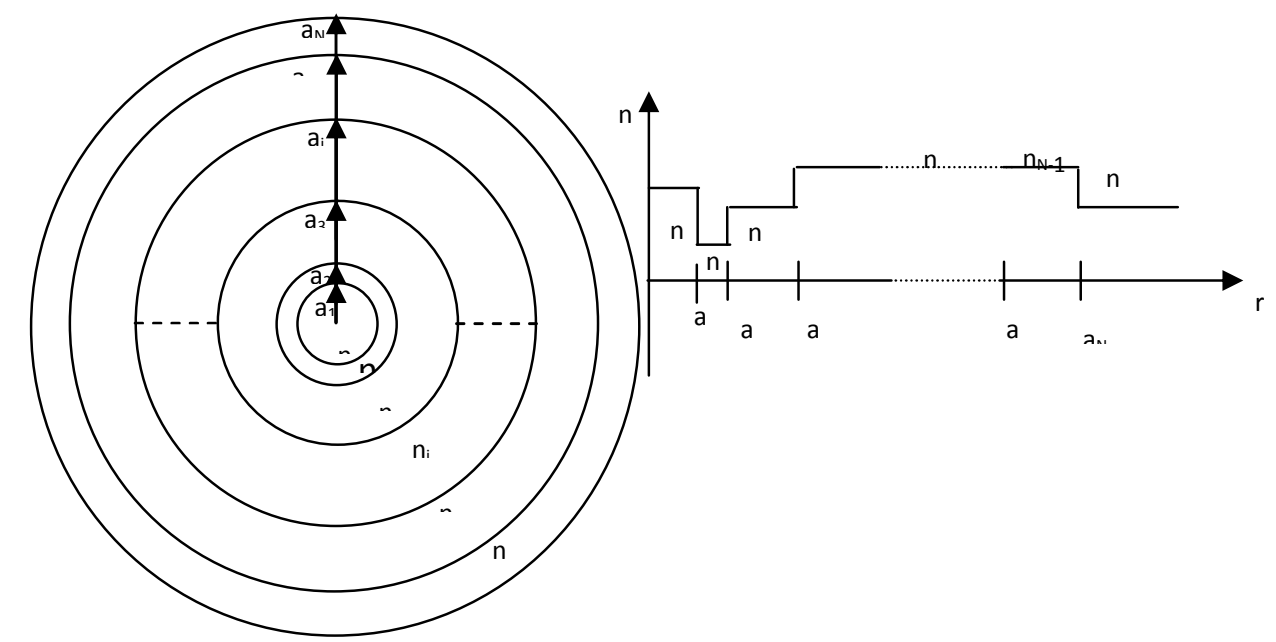

Figure. (1) Geometry and dimensions of a cylindrical multi-layer optical fiber.

By using the cylindrical coordinates $(r, \varphi, z)$, the homogeneous vector wave equation in cylindrical coordinates could be written as $[1,2]$ :

$$
\begin{aligned}
& \quad \frac{\partial^{2} \bar{\psi}}{\partial \mathrm{r}^{2}}+\frac{1}{\mathrm{r}} \frac{\partial \bar{\Psi}}{\partial \mathrm{r}}+\frac{1}{\mathrm{r}^{2}} \frac{\partial \bar{\psi}}{\partial \varphi^{2}}+q^{2} \bar{\Psi}=0 \\
& \text { the } \bar{\Psi} \text { representeitherE }\left(\mathrm{e}_{\mathrm{x}}, \mathrm{e}_{\mathrm{y}}, \mathrm{e}_{\mathrm{z}}\right) \operatorname{or} \mathrm{H}\left(\mathrm{h}_{\mathrm{x}}, \mathrm{h}_{\mathrm{y}}, \mathrm{h}_{\mathrm{z}}\right) \\
& \mathrm{q}^{2}=\left(\mathrm{k}^{2} \mathrm{n}^{2}-\beta^{2}\right) \\
& \Psi=\Psi(\mathrm{r}, \phi) \exp (-\mathrm{i} \beta \mathrm{z})
\end{aligned}
$$

By adopting weakly guided approximation technique, the refractive indices of the successive layers are nearly equal, and the longitudinal field components $\left(\mathrm{e}_{\mathrm{z}}, \mathrm{h}_{\mathrm{z}}\right)$ are very small compared to the transverse ones, and then can be neglected. In this case the field inside the optical fiber are quasi (TEM) (TEM: Transverse Electro-Magnetic), then the field can be described as linear combination of scalar modes oriented along transverse $(\mathrm{x}, \mathrm{y})$ plane. By adopting these approximations, it is possible to determine the propagation properties inside the fiber, which lead to construct a set of scalar equations with negligible error comparing with vector wave equations and these equations describe the field expansion in the successive circular strips of multi-layer fibers:

$$
\begin{aligned}
& \Psi(\mathrm{r}, \varphi)=\left[\mathrm{A}_{\mathrm{i}} \mathrm{J}_{0}\left(\mathrm{u}_{\mathrm{i}} \mathrm{r}\right)+\mathrm{B}_{\mathrm{i}} \mathrm{Y}_{0}\left(\mathrm{u}_{\mathrm{i}} \mathrm{r}\right)\right] \Phi(\varphi) \quad \text { if } \mathrm{n}_{\mathrm{i}}>\mathrm{n}_{\text {eff }} \\
& \Psi(\mathrm{r}, \varphi)=\left[\mathrm{A}_{\mathrm{i}} \mathrm{I}_{0}\left(\mathrm{u}_{\mathrm{i}} \mathrm{r}\right)+\mathrm{B}_{\mathrm{i}} \mathrm{K}_{0}\left(\mathrm{u}_{\mathrm{i}} \mathrm{r}\right)\right] \Phi(\varphi) \quad \text { if } \mathrm{n}_{\mathrm{i}}<\mathrm{n}_{\text {eff }}
\end{aligned}
$$


$A_{i}, B_{i}$ are constants (amplitude coefficients), $J_{0}, Y_{0}, I_{0}, K_{0}$ are the usual zero order Bessel functions and $\Phi(\varphi)$ is a common term and will be omitted from both sides of equations (9), and

$$
u_{i}=\left(\left|\beta^{2}-k^{2} n_{i}^{2}\right|\right)^{1 / 2}
$$

At origin $\mathrm{r}=0, \mathrm{Y}_{\mathbf{0}}$ Bessel function and $\mathrm{K}_{0}$ Bessel function must be excluded from the solution because they are undefined at origin. At final cladding layer, the solution is only $\mathrm{K}_{0}$ Bessel function. Other terms in the equation (9b) are omitted. However, for the other layers (from second to $\mathrm{N}-1$ layer) the solution to be considered by equations (9) is a combination of $\mathrm{J}_{0}\left(\mathrm{u}_{\mathrm{i}} \mathrm{r}\right)$ and $\mathrm{Y}_{0}\left(\mathrm{u}_{\mathrm{i}} \mathrm{r}\right)$ if $\mathrm{n}_{i}>\mathrm{n}_{\text {eff }}$ otherwise a combination of $\mathrm{I}_{0}\left(\mathrm{u}_{\mathrm{i}} \mathrm{r}\right)$ and $\mathrm{K}_{0}\left(\mathrm{u}_{\mathrm{i}} \mathrm{r}\right)$ if $\mathrm{n}_{i}<\mathrm{n}_{\text {eff. }}$

The tangential field component among the various successive layers should be continuous, i.e. $\Psi(\mathrm{r}, \phi)$ and its derivative $\partial \Psi / \partial \mathrm{r}$ are continuous at the boundaries. Depending on this condition, it is possible

$$
\begin{aligned}
& A_{i} M_{0}\left(u_{i} r\right)+B_{i} N_{0}\left(u_{i} r\right)=A_{i+1} M_{0}\left(u_{i+1} r\right)+B_{i+1} N_{0}\left(u_{i+1} a_{i}\right) \\
& \left.A_{i} \frac{d}{d r} M_{0}\left(u_{i} r\right)\right|_{r=a_{i}}+\left.B_{i} \frac{d}{d r} N_{0}\left(u_{i} r\right)\right|_{r=a_{i}}=\left.A_{i+1} \frac{d}{d r} M_{0}\left(u_{i+1} r\right)\right|_{r=a_{i}}+\left.B_{i+1} \frac{d}{d r} N_{0}\left(u_{i+1} r\right)\right|_{r=a_{i}}
\end{aligned}
$$

to write down the general relationship of the field and its derivative by the following relation for the $i^{\text {th }}$ layer from equation (9a) and (9b):

$\mathrm{M}_{0}\left(\mathrm{u}_{\mathrm{i}} \mathrm{r}\right)$ is the Bessel function of $1^{\text {st }}$ kind and it is equal to $\mathrm{J}_{0}\left(\mathrm{u}_{\mathrm{i}} \mathrm{r}\right)$; or modified Bessel function of $1^{\text {st }}$ kind and it is equal to $\mathrm{I}_{0}\left(\mathrm{u}_{\mathrm{i}} \mathrm{r}\right) . \mathrm{N}_{0}\left(\mathrm{u}_{\mathrm{i}} \mathrm{r}\right)$ is the Bessel function of $2^{\text {nd }}$ kind and it is equal to $\mathrm{Y}_{0}\left(\mathrm{u}_{\mathrm{i}} \mathrm{r}\right)$; or modified Bessel of $2^{\text {nd }}$ kind and it is equal to $\mathrm{K}_{0}\left(\mathrm{u}_{\mathrm{i}} \mathrm{r}\right)$.

Note the following special cases:

1. At the boundary between the core and $1^{\text {st }}$ layer, equations (10) become:

$$
\begin{aligned}
& \mathrm{A}_{1} \mathrm{M}_{0}\left(\mathrm{u}_{1} \mathrm{a}_{1}\right)-\mathrm{A}_{2} \mathrm{M}_{0}\left(\mathrm{u}_{2} \mathrm{a}_{1}\right)-\mathrm{B}_{2} \mathrm{~N}_{0}\left(\mathrm{u}_{2} \mathrm{a}_{1}\right)=0 \\
& \left.\mathrm{~A}_{1} \frac{\mathrm{d}}{\mathrm{dr}} \mathrm{M}_{0}\left(\mathrm{u}_{1} \mathrm{r}\right)\right|_{\mathrm{r}=\mathrm{a}_{1}}-\left.\mathrm{A}_{2} \frac{\mathrm{d}}{\mathrm{dr}} \mathrm{M}_{0}\left(\mathrm{u}_{2} \mathrm{r}\right)\right|_{\mathrm{r}=\mathrm{a}_{1}}-\left.\mathrm{B}_{2} \frac{\mathrm{d}}{\mathrm{dr}} \mathrm{N}_{0}\left(\mathrm{u}_{2} \mathrm{r}\right)\right|_{\mathrm{r}=\mathrm{a}_{1}}=0
\end{aligned}
$$

2. At the boundary between layer $(\mathrm{N}-1)$ and $(\mathrm{N})$, equations (10) become:

According to the set of equations (10,11 and 12) a system of (2N-2) equations

$$
\begin{aligned}
& A_{N-1} M_{0}\left(u_{N-1} a_{N-1}\right)+B_{N-1} N_{0}\left(u_{N-1} a_{N-1}\right)-A_{N} K_{0}\left(u_{N} a_{N-1}\right)=0 \\
& \left.A_{N-1} \frac{d}{d r} M_{0}\left(u_{N-1} r\right)\right|_{r=a_{N-1}}+\left.B_{N-1} \frac{d}{d r} N_{0}\left(u_{N-1} r\right)\right|_{r=a_{N-1}}-\left.A_{N} \frac{d}{d r} K_{0}\left(u_{N} r\right)\right|_{r=a_{N-1}}=0
\end{aligned}
$$


(2N-2) unknowns will be obtained. Avoiding a trivial solution, the determinant of coefficients for this system of equations must be equal to zero. Hence normalized propagation constant for a given range of wavelength and a specific mode for a given fiber will be obtained.

\section{Numerical Results and Discussion}

First of all, to demonstrate the validity of the method a step index fiber (one layer) and W-type (two layers) are considered. Fig (2) shows the results (which represent the dispersion versus wavelength) for these two types of optical fibers. The accuracy of this method when compared with [3] is less than $1 \%$. since the propagation constant could be found out, it is possible to calculate all the parameters of optical fiberFor multilayer fibers and here two types of theser fibers (two structures) will be considered, four layers and five layers optical fibers. Fig. (3) shows the refractive index profile and their dimensions of such fibers. The normalized propagation constant varying with wavelength for these fibers is illustrated in Fig. (4). The cutoff of the fundamental mode $\left(\mathrm{LP}_{01}\right)$ and the next higher mode $\left(\mathrm{LP}_{11}\right)$ are determined by these curves. Fig. (5) explains the normalized field distribution among the multi layers. The dispersion and the dispersion slope are shown in Fig. (6) and Fig. (7), respectively. A low dispersion over (1.4-1.6) $\mu \mathrm{m}$ band could be obtained with reasonable flatness. 

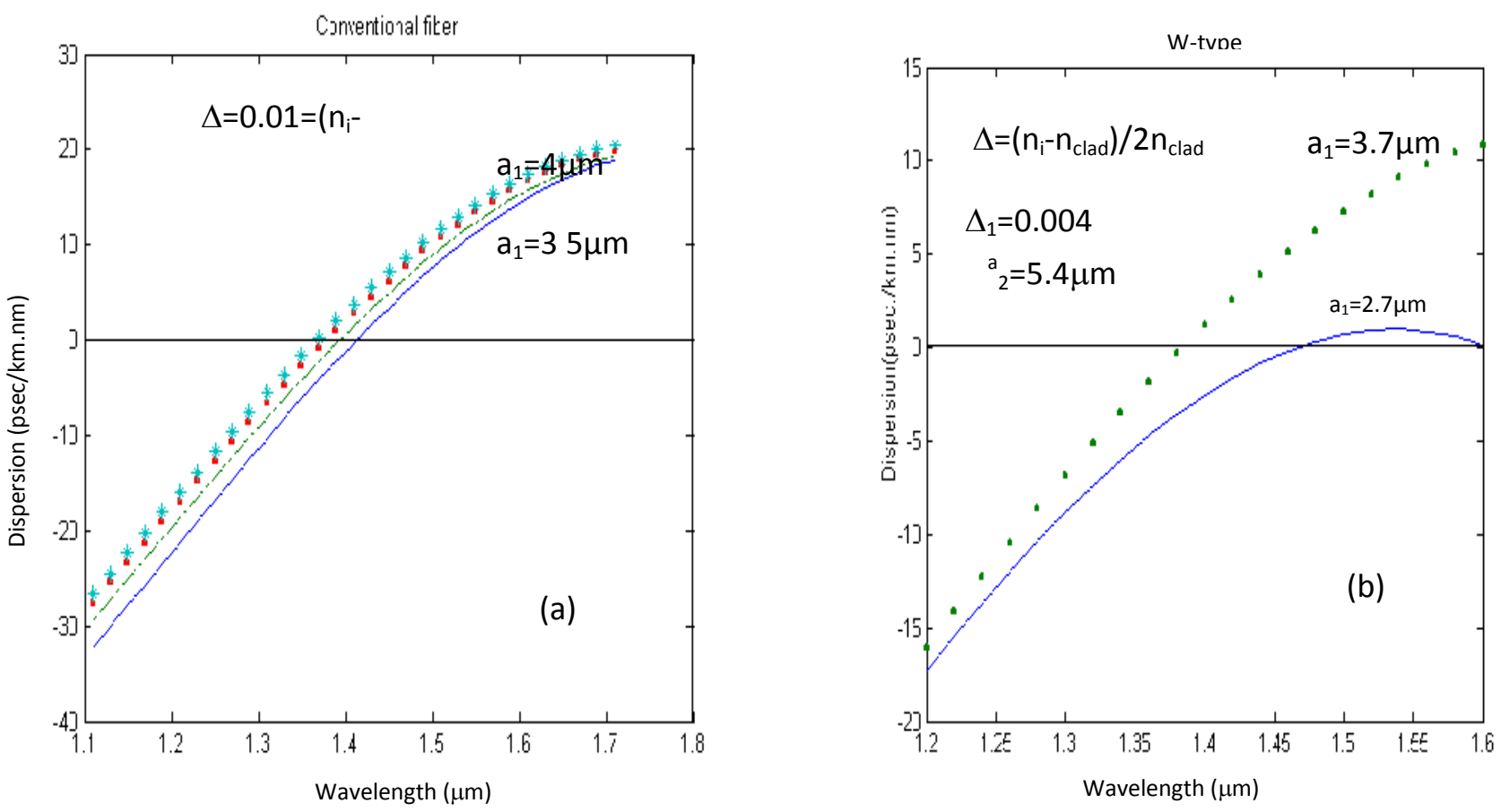

Fig. (2) The variation of dispersion versus wavelength.

(a) Conventional fiber \&(b) W-type
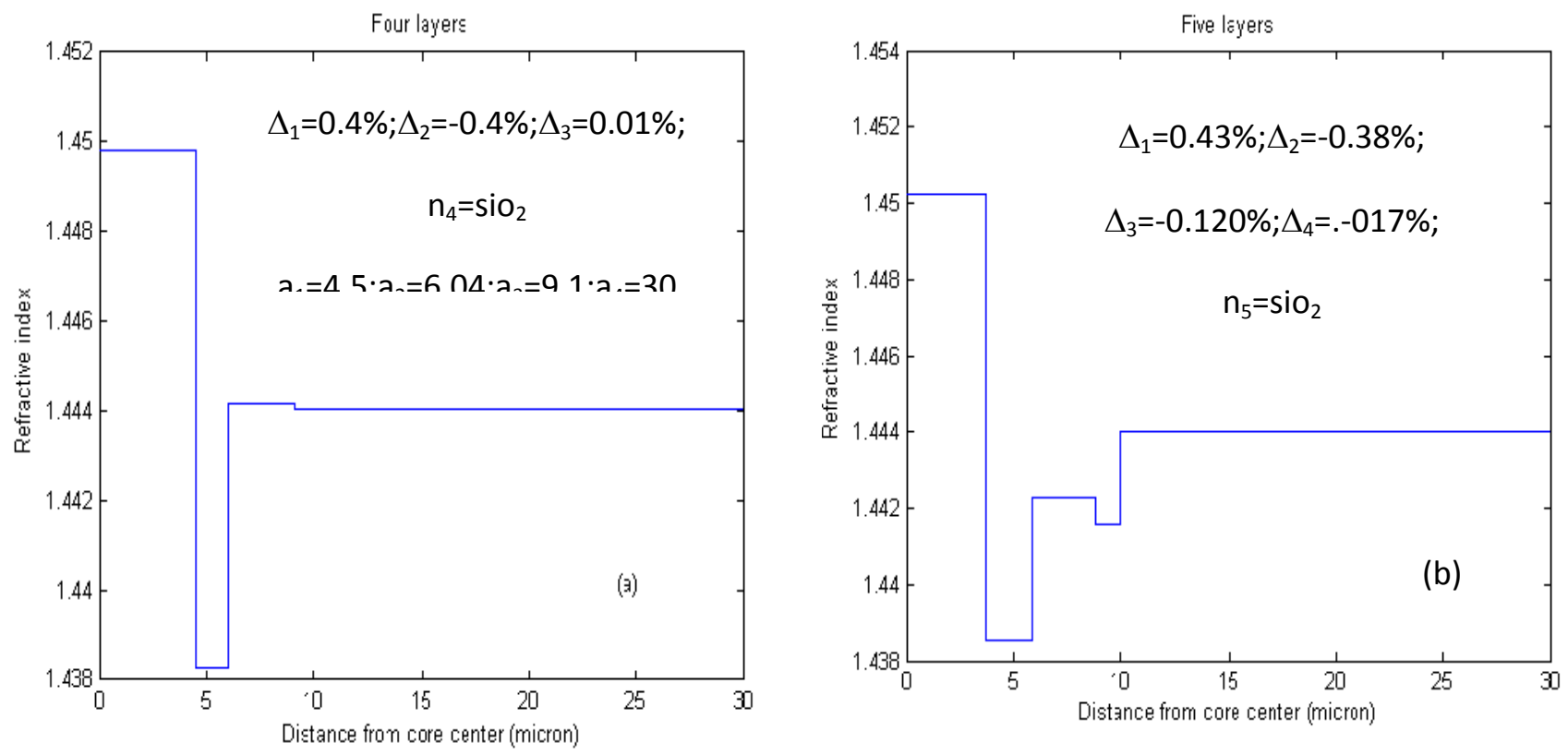

Fig. (3) The refractive index profiles \& their dimensions. 

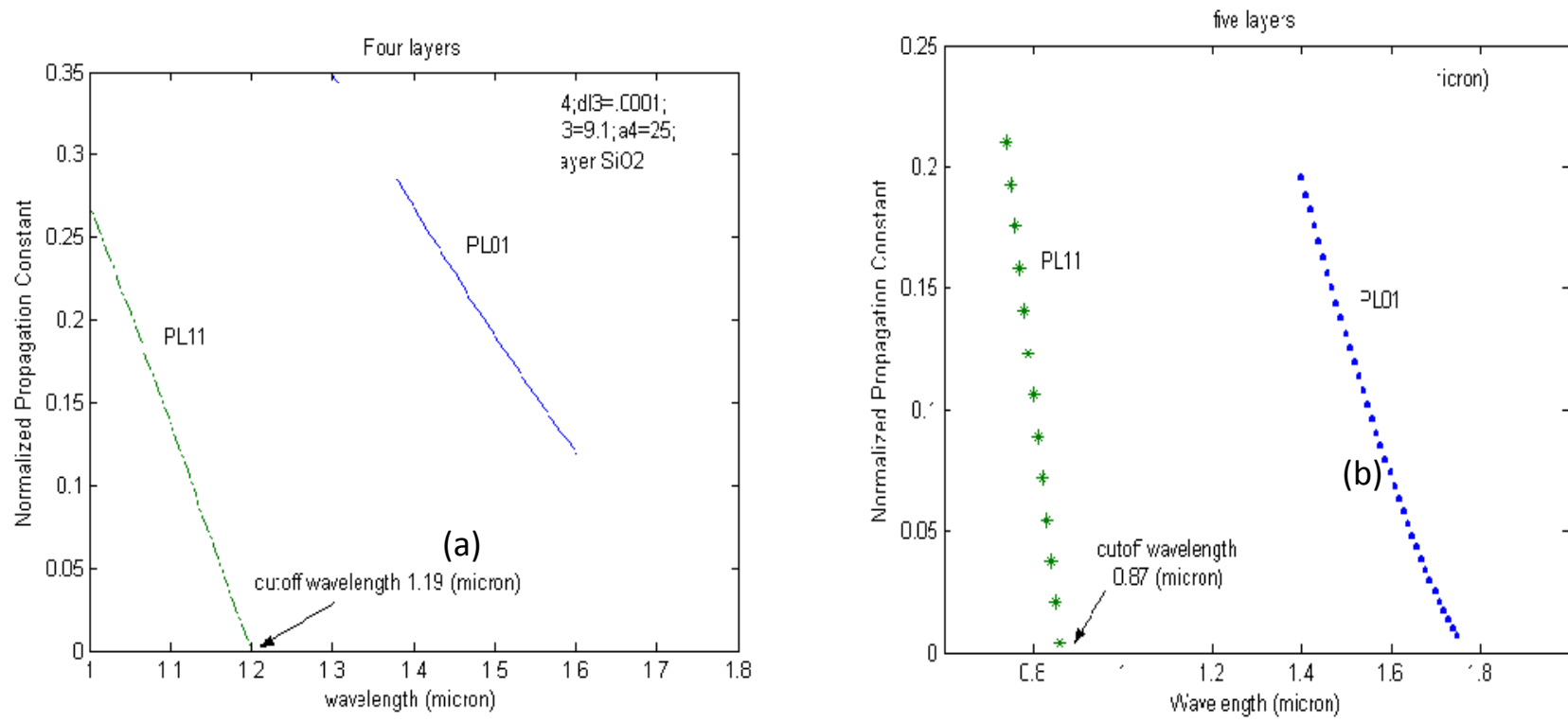

Fig. (4) The variation of normalized propagation constants versus wavelength.
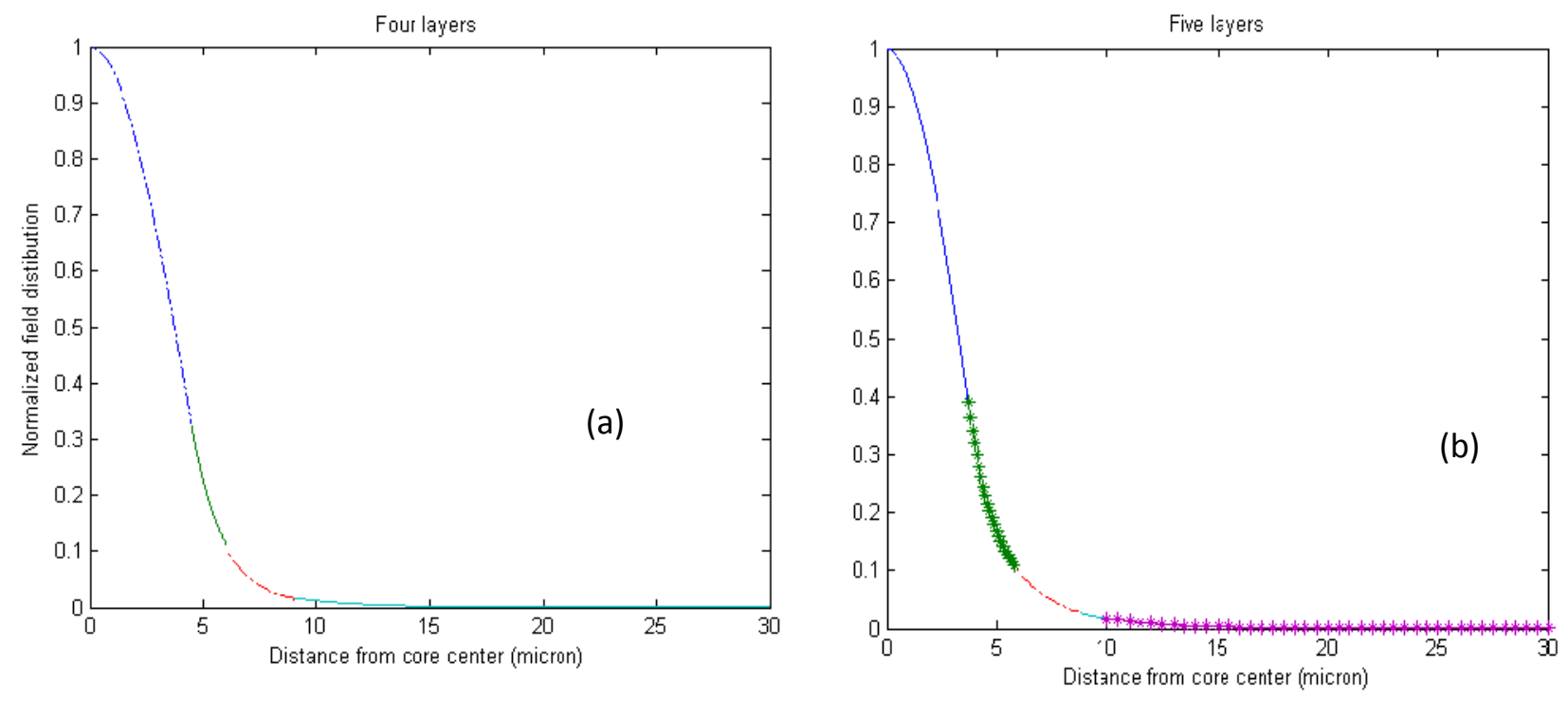


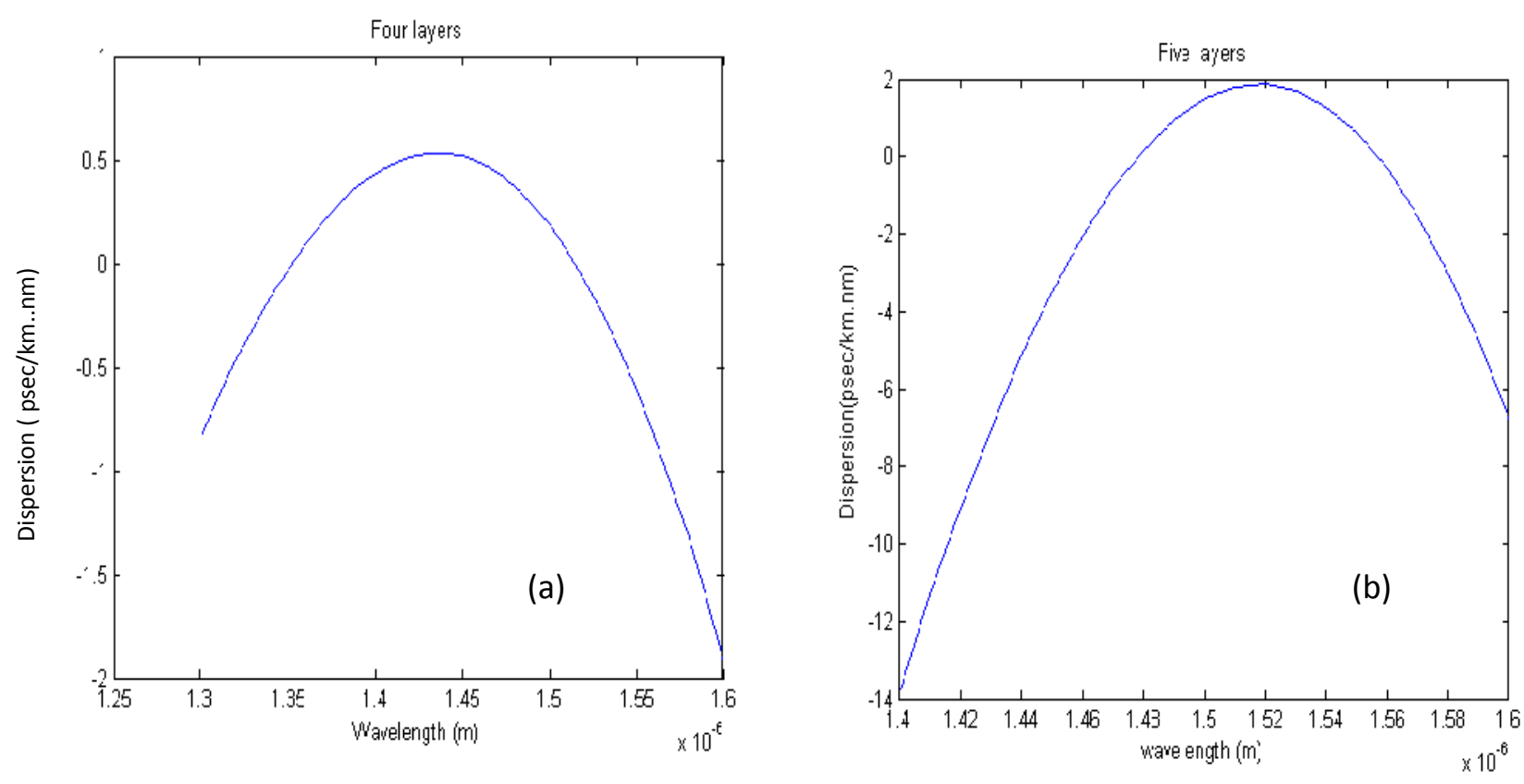

Fig. (6) The variation of dispersion versus wavelength.

(a) Four layers \&(b) Five layers.
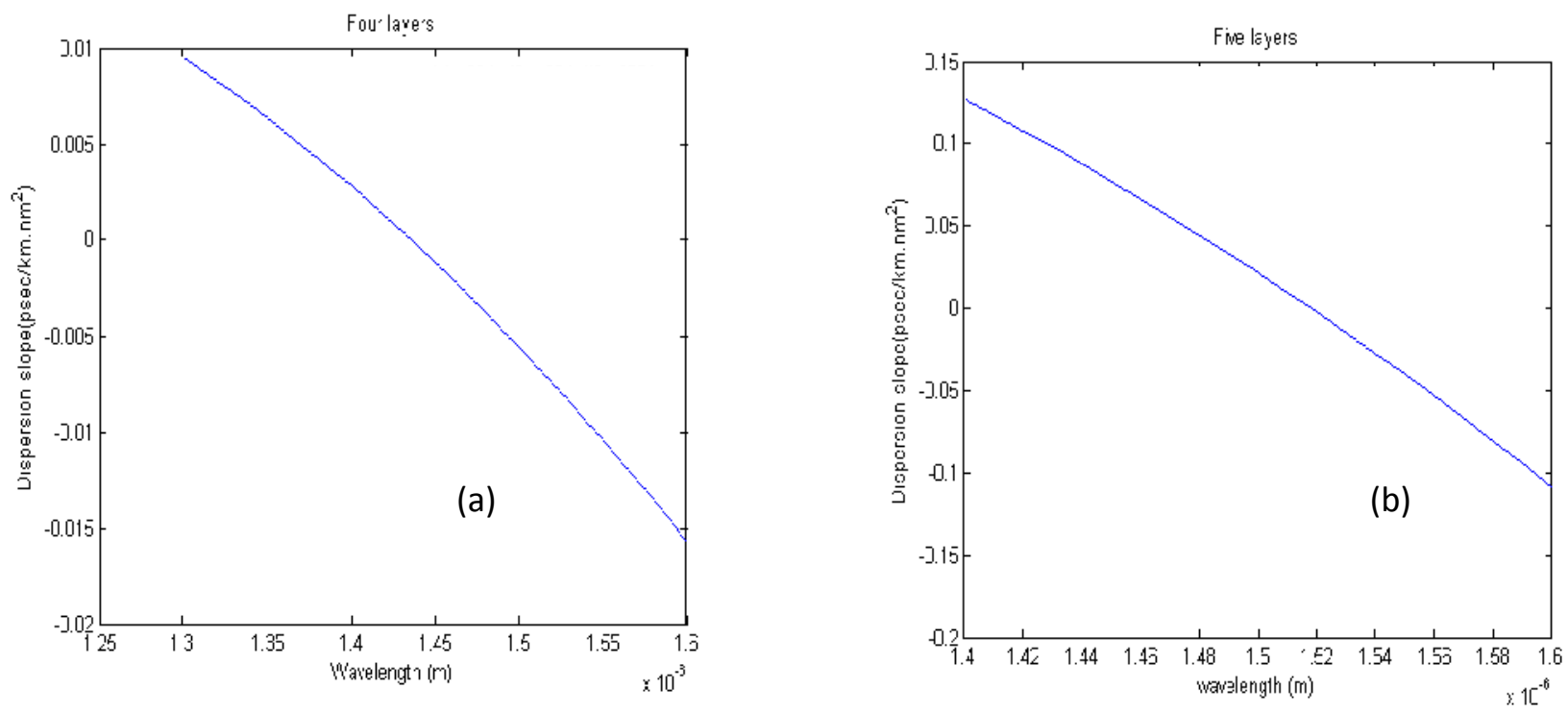

Fig. (7) The variation of dispersion slope versus wavelength.

(a) Four layers \&(b) Five layers. 


\section{Conclusion}

A suggestion of mathematical model to investigate the transmission properties of multi-layer optical fiber based on scalar wave equation is presented. These properties include cutoff wavelength, dispersion and dispersion slope. The model is designed throughout an effective mathematical representation of the concentric strips, which correspond to multi-layer refractive-index fibers. The necessary software programs to numerically calculating the various transmission properties were written in Matlab Version 6.5.

The calculated of near zero dispersion due to the design of these multi-layer fibers is very important for wavelength division multiplexing (WDM). It is possible to achieve high performance design by manipulating with the refractive index profile and fiber dimensions. This proposed analysis would establish a wide base for manufacturing optical fiber of multiple-layer structures, using the suggested mathematical model.

\section{$\underline{\text { References }}$}

1. M.J.Adams, "An Introduction to Optical Waveguides", John Wiley and Sons, Chichester, 1981.

2. H.J.R.Dutton, "Understanding Optical Communications", International Technical Support Organization, September 1998.

3. M.M.Shaker, M.M.Jasim and Q.A.Dawood, "Transmission Characteristic Analysis of Double-layer (W-Shape) Optical Fibers by Bisection Method", Al Rafideen Eng. Journal,Univ. of Mosul, Vol.10, No.1, 2001.

4. Q.Yu, Z.Pan, L.S.Yan and A.E.Willner, "Chromatic Dispersion monitoring technique using sideband optical filtering and clock phaseshift detection", Journal of Lightwave Technology, Vol. 20, No. 12, pp. 967-979, Dec.2002.

5. B. J. Ainslie and C.R.Day, "A Review of Single-Mode Fibers with Modified Dispersion Characteristics", Journal of Lightwave Technology, Vol. 4, pp. 967-979, August 1986.

6. Li, Yi and Yariv "Solutions to the Dynamical Equation of Polarization-Mode Dispersion and Polarization-Dependent Losses." Journal of the Optical Society of America B, Vol. 17, No.11., pp. 1821$1827,2000$. 
